\title{
Metal-Cam fiber/Epoksi/ÇDKNT Sandviç Panellerin Eğilme Davranışlarının Deneysel Olarak Araştırılması
}

\author{
Berkant Dindar \\ Tokat Gaziosmanpaşa Üniversitesi, Mühendislik ve Mimarlık Fakültesi, Makine Mühendisliği Bölümü, Tokat, Türkiye (ORCID: 0000-0003-1215-3621)
}

(International Symposium on Multidisciplinary Studies and Innovative Technologies (ISMSIT) 2020 - 22-24 October 2020)

(DOI: 10.31590 /ejosat.822564)

ATIF/REFERENCE: Dindar, B. (2020). Metal-Cam fiber/Epoksi/ÇDKNT Sandviç Panellerin Eğilme Davranışlarının Deneysel Olarak Araştırılması. Avrupa Bilim ve Teknoloji Dergisi, (Özel Sayı), 249-253.

\section{$\ddot{O} \mathbf{z}$}

Bu çalışmada E-cam/Epoksi kompozitler çoğul duvarlı karbon nanotüpler (ÇDKNT) ile modifiye edilerek E-cam/Epoksi/ÇDKNT nanokompozitler üretilmiştir. Nanokompozitler pirinç, bakır ve alüminyum ile yapıştırılarak metal/nanokompozit sandviç paneller elde edilmiştir. Çalışmanıı amacı sandviç panellerin bu üç farklı tasarım parametresinde eğilme dayanımı değerlerinin deneysel olarak tespit edilmesidir. Sandviç panellerin çekirdek kısmını oluşturan nanokompozitler $330 \mathrm{~g} / \mathrm{m}^{2}$ ağırlığındaki tek eksenli (unidirectional) E-cam kumaşlar ile takviye edilmiştir. Nanokompozitlerin matris kısmını oluşturan reçine ise diglisidil ether bisfenol A türü bir epoksidir. Modifiye malzemesi olarak kullanılan karbon nanotüplerin saflıkları \%98, iç çapları 5-10 nanometre dış çapları 10-20 nanometre ve 0,5-2 mikrometre aralığındadır. Karbon nanotüpler fonksiyonelleştirilmiş (-OH) olarak temin edilmiştir. Matris ve takviye elemanları arasındaki arayüzey bağları bir kompozit için en önemli noktalardan birtanesidir. Yükün matristen elyaflara dengeli aktarılması kompozitin bazı mukavemet değerlerini arttırmaktadır. Karbon nanotüpler fonksiyonel (-OH) guruplar ile kimyasal olarak epoksi reçineye bağlanmakta ve fiziksel olarak da E-cam elyaflara saplanarak bir köprü gibi işlev görerek arayüzey kalitesini arttırmaktadır. Karbon nanotüplerin bu işlevleri yerine getirebilmesi reçine içerisinde homojen karışmaları ile doğrudan ilişkilidir. Reçine sertleştirici karışımı \%70-30 yapıldıktan sonra ağırlıkça \%0,5 oranında ilave edilen nano partüküller mekanik olarak 20 dk. süre ile karıştırılmışlardır. Bu karışım bir el paleti ile E-cam kumaşlara uygulanmış ve sonrasında reçinenin kumaşa iyice difüze olması için 30 dk. bekletilmiştir. Bu sslak haldeki kumaşlar dört tabakalı şekilde [0] $]_{4}$ sıcak pres kalıplama ile $100{ }^{\circ} \mathrm{C}$ sıcaklık ve 7 bar basınç altında kürleştirilmişlerdir. Kürleşen plakalar ve pirinç, bakır, alüminyum levhalar su jeti ile deney numunesi ölçülerinde (100x20mm) ebatlandırılmışlardır. Sandviç panelin dış laminatlarını oluşturan pirinç, bakır, ve alüminyum ile çekirdeği oluşturan nanokompozit malzeme çift komponentli metil metakrilat ile yapıştırılmıştır. Son olarak üç nokta eğme deneyleri yapılan bu sandviç panellerin bükülmeye karşı en dayanıklısı $19 \mathrm{MPa}$ ile Alüminyum-Cam fiber/Epoksi/ÇDKNT, sonrasında $11 \mathrm{MPa}$, Bakır-Cam fiber/Epoksi/ÇDKNT son olarakda $10 \mathrm{MPa}$ ile Pirinç-Cam fiber/Epoksi/ÇDKNT olarak tespit edilmiştir.

Anahtar Kelimeler: Karbon nanotüp, E-cam, Epoksi, Pirinç, Bakır, Alüminyum.

\section{Experimental Investigation of Flexural Behavior of Metal-Glass fiber/Epoxy/MWCNT}

\begin{abstract}
In this study E-glass/Epoxy/MWCNT nanocomposites were produces by modifiying E-glass/epoxy composites with multi-walled carbon nanotubes (MWCNT). Metal/nanocomposite sandwich panels were obtained by bonding banocomposites with brass, copper and aluminum. The aim of study is to determine the bending strength values of sandwich panels in these three different design parameters experimentally. The nanocomposites forming the core part of the sandwich panels are reinforced with $330 \mathrm{~g} / \mathrm{m}^{2} \mathrm{unidirectional} \mathrm{E-glass}$ fabrics. The resin that forms the matrix part of nanocomposites is a diglycidyl ether bisphenol A type epoxy. The purity of carbon nanotubes used as modification material is 98\%, inner diameters of 5-10 nanometers, outer diameters of 10-20 nanometers and 0,5-2 micrometers. Carbon nanotubes functionalized as $-\mathrm{OH}$ were imported from Switzerland. Interfacial bonds between matrix an reinforcement elements are one of the most important points for a composite. The balanced transfer of the load from the matrix to the fibers increases some of the strength values of the composite. Carbon nanotubes are chemically bonded to epoxy resin with functional
\end{abstract}


$(-\mathrm{OH})$ groups and physically stuck to E-glass fibers acting as a bridge, increasing the quality of the interface. The ability of carbon nanotubes to fulfill these functions is directly related to their homogeneous mixing within the resin. After the resin hardener mixture is made $80-20 \%$, the nanoparticles added at $0.5 \%$ by weight are mechanically $20 \mathrm{~min}$. have been mixed for time. The mixture is applied to E-glass fabrics with a hand palette and then $30 \mathrm{~min}$. to allow the resin to diffuse into the fabric thoroughly has been suspended. These wet fabrics were cured in four layers $[0]_{4}$ with hot press molding at $100{ }^{\circ} \mathrm{C}$ and 7 bar pressure. Cured plates and brass, copper aluminum plates were sized with water jet to test sample dimensions (100x20). Brass, copper and aluminum forming the outer laminate of the sandwich panel and the nanocomposite material forming the core are bonded with methyl methacrylate with two components. Finally, the three-point bending tests of these sandwich panels are the most resistant to bending with 33 MPa, Aluminum-Glass fiber/Epoxy/MWCNT then $11 \mathrm{MPa}$, Copper-Glass fiber/Epoxy/MWCNT and $10 \mathrm{MPa}$ were determined.

Keywords: Carbon nanotub, E-glass, Epoxy. Brass, Copper, Aluminum.

\section{Giriş}

Sandviç yapıların kullanımı, uygulama alanlarının genişliği nedeniyle hızla artmaya devam etmektedir, örneğin; uzay araçlarında, uçaklarda, deniz araçları, kamyon yapıları, tren ve konteynerların yanı sıra bazı otomobil gövde parçalarında kullanılırlar. Kompozit sandviç paneller genellikle iki ince yüzey malzemesinden ve yüzey malzemesine göre nispeten kalın bir çekirdek malzemeden oluşur(Mingze vd., 2020). Sandviç panelin orta kısmını oluşturan çekirdek elemanlar balsa, kontrplak gibi doğal malzemelerden oluşabildiği gibi petek, köpük, kompozit gibi, yüksek mühendislik malzemelerine kadar çeşitlilik gösterebilmektedir. Bundan dolayı sandviç kompozitlerin mekanik davranışları, çekirdek elemanın özellikleri ile yakından ilişkilidir(Efe, 2019). Kompozit sandviç yapıları kullanmanın sayısız avantajına rağmen, düzlem dışı darbe hasarına karşı son derece hassastırlar(Alamin vd., 2018). Sandviç panellerin davranışı temel olarak geometrik konfigürasyona ve çekirdek ve kaplamanın malzemelerine bağlıdır (Hussain vd., 2019). Sandviç panellerin göçme davranışı da geometrik konfigrasyonlarına, malzeme türlerine, ve yükleme düzenine bağlıdır. Bu nedenle sandviç panellerin arıza mekanizmalarını ayrı ayrı araştırmak gerekir(Sakly vd., 2016). Sandviç yapı imalatının en yaygın amacı minimum toplam yoğunlukta (ortalama) en büyük sertliği elde etmektir(Krzyhak vd., 2016). Son zamanlarda sandviç panellerin davranışları üzerine pek çok çalışma yayınlanmıştır. Bazı sandviç yapıların temelleri ve deneysel araştırmaları (Dai vd., 2003; Engin vd., 2008; Mostafa., 2014; Iyer vd., 2017) tarafindan açıklanmıştır.

Nanokompozitlere yönelik çalışmalar: Fiber ve matris arasındaki bağın, fiber takviyeli polimerlerin genel özelliklerinde çok önemli bir rol oynadığı iyi bilinmektedir. Zayıf fiber matris ara yüzey bağları olması gereknden düşük yüklerde hasar meydana getirebilir ve sonuç olarak fiber takviyeli polimerlerin nihai mukavemeti azalır(Qingyu vd., 2013). Nano partiküller arayüzey yapışmasını arttırmada dikkate değer bir etki göstermiştir. Nanopartiküller, fazlar içinde birbirine kenetlenen pimler gibi hareket ederek fiber ile matris arasında daha yüksek bir sürtünme oluşturabilir. Karbon nanotüplerin kompozit malzeme özelliklerini değiştirme gücüne sahip oldukları aşikardır. Karbon nanotüpler polimer matris içinde dolgu maddeleri olarak kullanılarak yeni özellikte malzemeler elde edilebilir (Gao vd., 2015; Mittal vd.2015; Tian vd., 2017). Çok duvarlı karbon nanotüpler, çok geniş en-boy oranı ve yüksek modüllü dolgu maddeleri olarak polimerik matriste obimal oranlarda (Eskizeybek 2012) kullanıldığında, iyi takviye verimlilikleri gösterdikleri deneysel olarak kanıtlanmıştır (Mortone vd., 2010). Cam dokuma takviyeli epoksi kompozitin mekanik özellikleri, çoğul duvarlı karbon nanotüpler eklenmesiyle iyileşmektedir. (Shivamurthy vd., 2020)

Bükülmeye yönelik çalışmalar: Gemi gövdelerinde kullanıldığında, sandviç yapılar çoğunlukla bükülme yüküne maruz kalır (Hou vd., 2018). Cam/epoksi kompozite nanosilika (epoksinin ağırlıç̧a\% 1'i kadar) ve nanokil (epoksinin ağırlıkça\% 2'si kadar) ilave edilmesi, nanokompozitin bükülme mukavemetinde \% 10.81 artış sağlamıştır. (Nayak, vd., 2020). Fiber takviyeli polimerik yapılar ve Al6063T5 alüminyum birlikte kullanılmasıyla hibrid yapılar elde edilmiş ve bu yapının numerik olarak eğilme davranışları araştırılmıştır. Analizler sonucunda ilk önce karbon takviyeli kompozitte delaminasyon meydana oluşmuş daha sonra alüminyum ve kompozit arasındaki bağlar açılmış ardından da alüminyumun burkulması ve hibrit kirişin bükülmesi ile çökme meydana gelmiştir (Shin, vd. 2014). Eksenel bükülme çökmesi altında enerji absorpsiyon kabiliyetini araştırmak üzere alüminyum/cam fiber takviyeli polimerik hibrid kare tüpler üretilmiştir. Eksenel bükülme koşullarında alüminyum tüpe göre daha hafif olan hibrid tüp iyi bir enerji soğurma kabiliyeti göstermektedir (Shin, vd. 2002). Tasarım optimizasyonu, tüm bu faktörlerin etkilerini göz önünde bulundurmanın, uygun yapısal parametreleri belirlemenin ve metal/kompozit hibrit tüplerin dayanıklılığını iyileştirmenin umut verici bir yoludur (Sun. vd., 2019; Yu. vd., 2019). Farklı çelik/polimer/çelik sandviç kompozit kombinasyonlarının eğilme davranışı deneysel, sayısal ve analitik olarak incelenmiştir. Daha kalın çekirdeklerde daha az geri esneme öngörülmüş ancak azalan geri esneme ile birlikte kılın çekirdeklerin dış katmanındaki çekme gerimesinin artmasından dolayı çatlama olasılığıda artmaktadır (Harhasha, vd.2020).

$\mathrm{Bu}$ çalışmada ise sandviç panellerin, farklı tasarım parametrelerinin eğilme davranışlarına etkisi incelenmiştir. Sandviç panelller prinç, bakır ve alüminyum yüzey tabakalarının bir yapıştırıcı ile tek yönlü [0]4 E-cam/epoksi/ÇDKNT çekirdek elemana yapıştırılmasıyla üretilmiştir. Deneysel olarak üç noktadan eğilmeye tabi tutulan bu sandviç panellerin dayanımına yönelik bir analiz sunulmuştur.

\section{Materyal ve Metot}

\subsection{Malzemeler}

Çalışmada kullanılan sandviç panellerin nanokompozit çekirdek kısmınında $330 \mathrm{~g} / \mathrm{m}^{2}$ ağırlığındaki tek eksenli (unidirectional) Ecam kumaşlar kullanılmıştur. Bu kumaşlar İzmir Kompozitsan şirketinden temin edilmiştir. Nanokompozitlerin matris kısmını oluşturan e-ISSN: $2148-2683$ 
reçine ise diglisidil ether bisfenol A türü bir epoksidir bu epoksi ve sertleştiricisi yine İzmir'de faliyet gösteren Meduza Karbon şirketinden temin edilmiştir. Modifiye malzemesi olarak kullanılan karbon nanotüplerin saflıkları \% 98 , iç çapları 5-10 nanometre dış çapları 10-20 nanometre ve 0,5-2 mikrometre aralığındadır. Karbon nanotüpler - $\mathrm{OH}$ olarak fonksiyonelleştirilmiş olarak tercih edilmiştir.

\subsection{Deney Numunelerinin Üretilmesi}

Reçine sertleştirici karışımı \%70-30 yapıldıktan sonra hassas terazide ağırlıkça \%0,5 oranında tartılan (Şekil 1(a)) karbon nanotüpler reçineye ktılmış ve mekanik olarak $20 \mathrm{dk}$. süre ile karıştırılmışdır. Bu karışım manüel olarak E-cam kumaşlara uygulanmış (Şekil 1(b) ) ve sonrasında reçinenin kumaşa iyice difüze olması için $30 \mathrm{dk}$. bekletilmiştir. Bu 1slak haldeki kumaşlar dört tabakalı şekilde $[0]_{4}$ sıcak pres kalıplama ile $100{ }^{\circ} \mathrm{C}$ sıcaklık ve 7 bar basınç altında kürleştirilmişlerdir. Kürleşmeden sonra plakaların kenarlarında oluşan reçine çapakları bir elektrikli testere ile traşlanmıştır. Daha sonra kompozit plakalar ve pirinç, bakır, alüminyum levhalar su jeti ile deney numunesi ölçülerinde $(100 \times 20 \mathrm{~mm})$ ebatlandırılmışlardır.
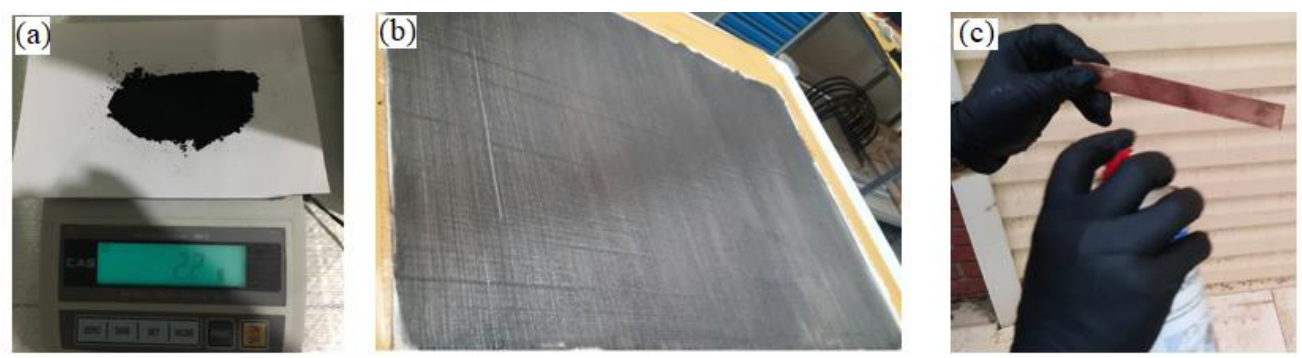

Şekil 1. Karbon nanotüplerin tartılması (a), E-cam kumaşlara epoksi/ÇDKNT(ă̆ırlıkça \%0,5) karışımının uygulanması (b), yapıştırma yüzeylerinin Weicon genel temizleyici srey ile temizlenmesi (bakır eleman).

Sandviç panelin dış lamnatlarını oluşturan pirinç, bakır ve alüminyum ile çekirdeği oluşturan nanokompozit malzemenin yapıştırma işlemleri Pamukkale Üniversitesei Makanik Laboratuvarında yapılmıştır. Numuneler yapıştırılmadan önce yüzeyleri önce bir döner keçe ile parlatılmış ve sonrasında Weicon genel temizleyici sprey (Şekill (c)) ile temizlenmiştir. Temizlik işlemi yapıldıktan sonra elemanlar ortam şartlarında çift komponentli metil metakrilat ile yapıştırılmış ve yapıştırıcının kürleşmesi için üç gün beklemeye alınmıştır.

\subsection{Deneysel Çalışmalar}

Deney numuneleri yapıştırmadan sonra (Şekil 2(a))'daki nihai hallerini alarak deneylere hazır hale gelmişlerdir. Sandviç yapıların eğilme özellikleri Instron $8801(50 \mathrm{kN})$ servo hidrolik deney cihazı ile Pamukkale Üniversitesi, Mekanik Laboratuvarında ortam sıcaklığı ve ortam nem koşullarında $1 \mathrm{~mm} / \mathrm{dk}$ bası hızında deplasman kontrollü olarak yapılmıştır. Deney numunelerinin yapısı ve ölçüleri (Şekil 2 (b))'deki teknik resim çiminden görüldüğü üzere 100x20mm en boy mesfesindre ve 2 adet $0,5 \mathrm{~mm}$ kalınlığında metal dış yüzey elemanı, yaklaşık $0,15 \mathrm{~mm}$ kalınlığında 2 adet yapıştıııcı bölgesi ve çekirdeği oluşturan $1 \mathrm{~mm}$ kalınlığındaki nano kompozit şeklindedir. (Şekil 3(b))'de üç nokta eğme aparatı ve Prinç-Cam fiber/Epoksi/ÇDKNT numuneye ait bir üç nokta eğme deneyi görülmektedir.
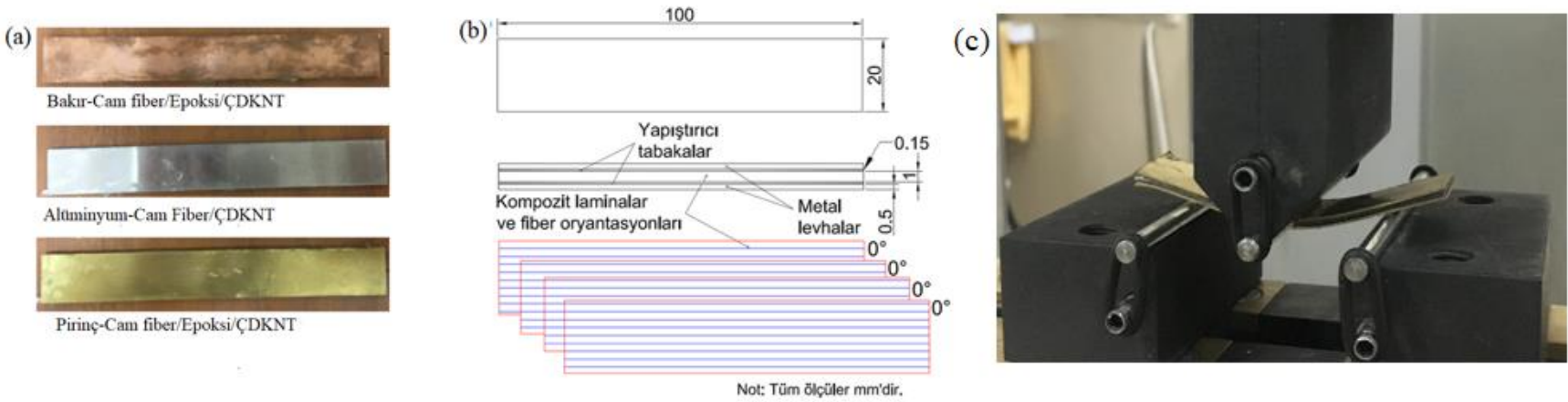

Şekil 2 Sandviç yapılı deney numuneleri (a), sandviç yapının teknik resim çizimi ve oryantasyon açıları (b) nokta eğme deneyi (Pirinç-Cam fiber/Epoksi/ÇDKNT) (c).

\section{Araştırma Sonuçları ve Tartışma}

Matris ve takviye elemanları arasındaki arayüzey bağları bir kompozit için en önemli noktalardan birtanesidir. Yükün matristen elyaflara dengeli aktarılması kompozitin tabakalar arası kırılma tokluğunu etkileyen en önemli faktörlerdendir kırılma tokluğu aynı zamanda bükülme dayanımı ile doğrudan ilişkilidir. Bu bağlamda karbon nanotüpler fonksiyonel (-OH) guruplar ile kimyasal olarak epoksi reçineye bağlanmakta ve fiziksel olarak da E-cam elyaflara saplanarak bir köprü gibi işlev görerek arayüzey kalitesini arttırmaktadır. Üç nokta eğme deneyleri yapılan bu sandviç panellerin bükülmeye karşı en dayanıklısı $570 \mathrm{~N}$ ile Alüminyum-Cam fiber/Epoksi/ÇDKNT, sonrasında $330 \mathrm{~N}$, Bakır-Cam fiber/Epoksi/ÇDKNT son olarakda $300 \mathrm{~N}$ ile Pirinç-Cam fiber/Epoksi/ÇDKNT olarak tespit edilmiştir(Şekil 3(a)). Eğilme modülleri alüminyum, bakır,pirinç yüzey laminatlı numunelerde sırasıyla yaklaşık olarak 16, 
6 ve 4 GPa'dır (Şekil 3 (b)). Eğilme gerilmeleri ise yine aynı sıralama ile yazılırsa 19 MPa alüminyum laminatlı, 11 MPa Bakır laminatlı ve $10 \mathrm{MPa}$ pirinç laminatlı şekiklindedir (Şekil 3(c)) .
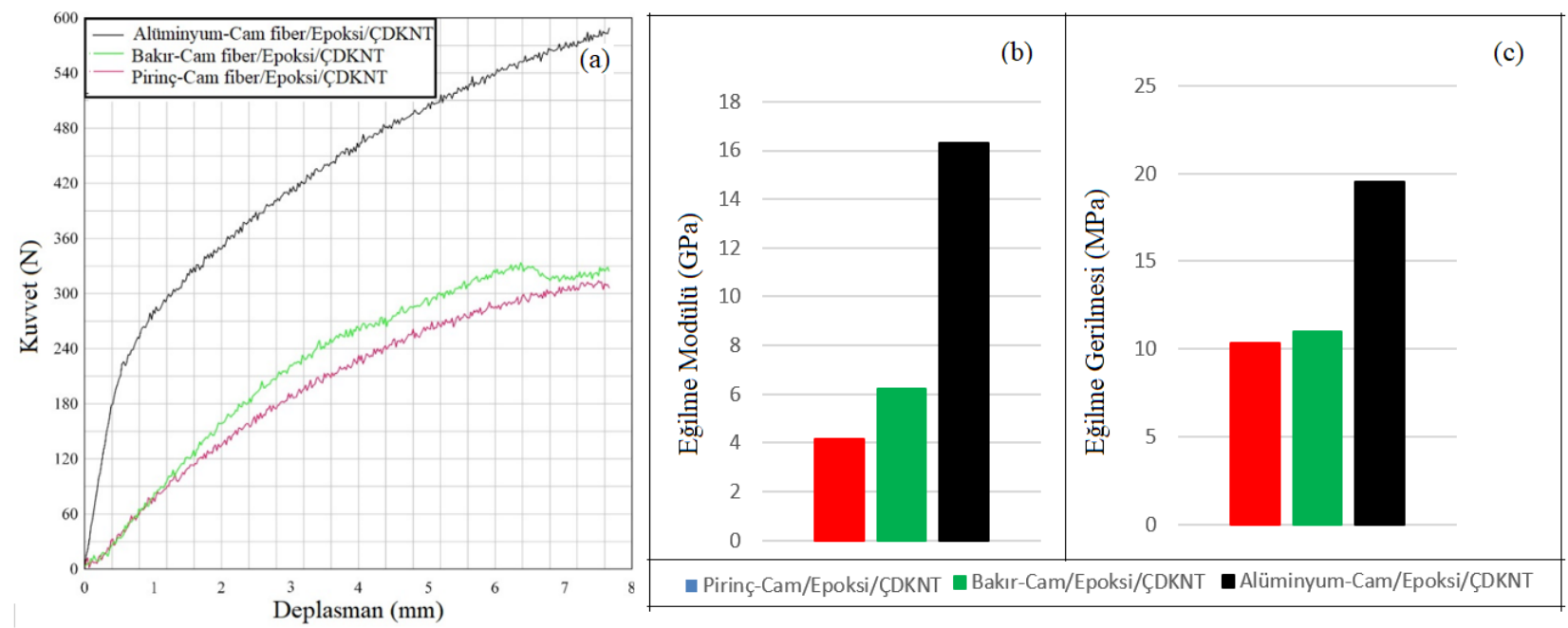

Şekil 3. Ü̧̧ nokta eğme değerleri; kuvvet-yüzde uzama grafiği(a), eğilme modülleri (b), eğilme gerilmesi (c).

Mesnet ve kuvvet noktaları (Şekil 4(a))'da gösterilmiştir. Kuvvet numuneye tam orta noktasından etki etmektedir. Bu kiriş sisteminde meydana gelen normal gerilmeler yüzey elemanında maksimum olmaktadır, $F$ yükünün uygulandığ 1 metal laminat'ta maksimum bası gerilmesi oluşmakta alttaki mesnet noktlarına karşılık gelenmetal laminat'ta ise maksimum çeki gerilmesi oluşmaktadır. Kesme gerilmeleri ise tarafsız eksende maksimum olmakta ve yüzeydeki metal elemanlara yaklaştıkça gerilme azalarak ve en diş noktalarda minimum seviye gelmektedir(Şekil 4 (b)).
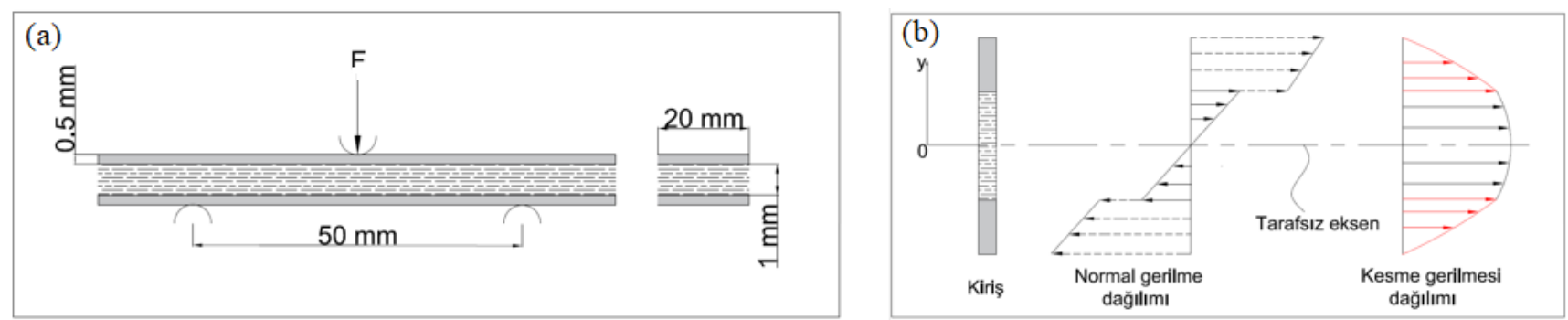

Şekil 4. Sandviç deney numunesinin mesnet ve kuvvet noktaları (a), deney numunesi üzerindeki gerilme dağıllmları (b).

\section{Sonuç}

Üç farklı konfigrasyonda üretilmiş bu sandviç yapıların üç nokta eğme deneyleri yapılmış ve aşağıdaki sonuçlara varılmıştır;

Pirinç-Cam fiber/Epoksi/ÇDKNT sandviç yapılar en düşük bükülme dayanımını sergilemişlerdir, Bakır-Cam fiber/Epoksi/ÇDKNT yapıların yaklaşık olarak \%8 oranında bu kompozitlere göre bükülme bakımından daha mukavim olduğu tespit edilmiş̧ir. AlüminyumCam fiber/Epoksi/ÇDKNT sandviç yapılar ise bükülmeye karşı diğer iki konfigrasyona kıyasla oldukça iyi performans göstermiştir. Öyle ki pirinç laminatlı sandviçlerden yaklaşık \%77 bakır laminatlı kompozitlerden ise \%88 oranında bükülmeye karşı daha mukavimdirler.

$\mathrm{Bu}$ üç sandviç yapıda nanokompozit çekirdeğin yüzey metalleri ile sinerj içinde çalışması kabul edilebilir eğilme özellikleri ortaya çıkarmıştır. Bu uyumlulukdan dolayı bu yapıların bazı endüstriyel ürünlerde kullanımına dair olumlu düşünceler oluşmuştur.

\section{Kaynakça}

Dai, J. ve Hahn, T.H. (2003). Flexural behavior of sandwich beams fabricated by vacuum-assisted resin transfer molding. Composite Structures, 61(3), 247-253.

Efe, M.O. (2019). Farklı destek mesafelerinde polivinil klorür (PVC) çekirdek yapılı sandviç kompozitlerin eğilme davranışlarının numerik analizi. Yüksek lisans tezi, Balıkkesir Üniversitesi, Balıkkesir.

Elamin, M., Li, B., Tan, K.T., (2018) Impact damage of composite sandwich structures in arctic condition. Composite Structures, 192, $422-433$.

Engin, M.R. ve Rizkalla, S.H. (2008). Material characteristics of 3-D FRP sandwich panels. Construction and Bulding Materials, 22, 1009-1018.

Eskizeybek, V. (2012). Yüzeylerine kimyasal olarak karbon nanotüpler bağlanmış örgü cam fiber/epoksi nanokompozitlerin üretimi ve tabakalar arası kırılma davranışlarının incelenmesi. Doktora tezi, Selçuk Üniversitesi, Konya,

Gao X., Gillespie J.W., Jensen, R.E., Li, V., Haque B.Z., McKnight S. M., (2015).Effect of fiber surface texture on the mechanical properties of glass fiber reinforced epoxy composite. Composites: Part A, 74, 10-17.

e-ISSN: 2148-2683 
Harhasha, M., Gilbertb, R.R., Hartmannb, S., Heinz, P., (2020). Experimental characterization, analytical and numerical investigations of metal/polymer/metal sandwich composites - Part 2: Free bending. Composite Structures, 232, 1-15.

Hou, P., Zhao, a., Wu, W., Huan, H., Li, C., Wang, S., Zhao, H., (2018). Failure mechanism of glass-fiber reinforced laminates influenced by the copper film in three-point bending. International Journal of Adhesion and Adhesives, 84, 368-377.

Hussain, M., Khan, R., Abbas, N., (2019). Experimental and computational studies on honeycomb sandwich structures unde static and fatigue bending load. Composite Structures, Journal of King Saud University-Science, 31, 222-229.

Iyer, V.S., Chatterjee, R., Ramya, M., Suresh, E., Padmanabhan, K., (2017). A comparative study of the three point and four point bending behaviour of rigid foam core glass/epoxy face sheet sandwich composites. Materials Today: Proceedings 5(5), 1208312090.

Krzyhak, A., Mazur, M., Gajewski, M., Drozd, K., Komorek, A., ve PrzybyBek, P., (2016). Sandwich structured composites for aeronautics: Methods of manufacturing affecting some mechanical properties. International Jour. of Aerospace Engineering, 1-10.

Mingze, M., Weixing, Y., Wen, J., Wei, J., Yan, C., Piao L., (2020). Fatigue behavior of composite sandwich paneles under three point bending load. Polymer Testing, 91, 1-8.

Mittal, G., Dhand, V., Rhee K.Y., Park1, S., Lee, W.R., (2015). A review on carbon nanotubes and graphene as fillers in reinforced polymer nanocomposites. Journal of Indistrial and Engineering Chemistry, 21, 11-25.

Mortone, A., Formicola C., GiordanoM., Zarrelli M., (2010). Reinforcement efficiency of multi-walled carbon nanotube/epoxy nanocomposites. Composites Science and Technology, 70, 1154-1160.

Mostafa, A., Shankar, K., ve Morozov, E.V., (2014) Experimental, Theoretical and numerical investigation of the composite sandwich panels with PVC foam core. Applied Composite Materials, 21(4), 661-675.

Nayak B.A., Shubham., Prusty, R.K., Ray, B.C. (2020). Effect of nanosilica and nanoclay reinforcement on flexural and thermal properties of glass fiber/epoxy composites. Materials Today: Proceedings, doi:0000000/000000000000

Qingyu, P., Yibin, L., Xiaodong, H., Hongzhen, L., Pingan. H., Yuanyuan. S., ... Shanyi D., (2013) Interfacial enhancement of carbon fiber composites by poly (amido amine) functionalization. Composites Science and Technology, 74, 37-42

Shivamurthy, B., Anandhan, S., Bhat, K.U., Thimmappa, B,H,S, (2020). Structure-property reletionship of glass fabric/MWCNT/epoxy multi layered laminates. Composites Communications, 22, 1-8.

Sakly, A., Laksimi, A., Kebir, H., Benmedakhen, S. (2016) Experimental and modelling study of low velocity impacts on composite sandwich structures for railway applications. Engineering Failure Analysis, 68, 22-31.

Shin, D.K., Kim, H.C., Lee, J.J., (2014). Numerical analysis of the damage behavior of an aluminum/CFRP hybrid beam under three point bending. Composites: Part B, 56, 397-404.

Shin, K.C, Lee, J.J, Kim, K.H., Song, M.C., Huh, J.S. (2002). Axial crush and bending collapse of an aluminium/GFRP hybrid square tube and its energy absorption capability. Composite Structures, 57, 279-287.

Wei, X., Wua, Q., Gao, Y., Xionga J., (2020). Bending characteristics of all-composite hexagon honeycomb sandwich beams: experimental tests and a three-dimensional failure mechanism map. Mechanics of Materials, 148, 1-10.

Xiong, J., Ma, L., Stocchi, A., Yang, J., Wu, L., Pan, S., (2014) Bending response of carbon fiber composite sandwich beams with three dimensional honeycomb cores, Composite Structures 108, 234-242. 